\title{
Effect of the Ukrainian Crisis on the Current Measles Situation and ways of Improving Surveillance
}

\author{
Tetyana Chumachenko*1, Dmytro Chumachenko ${ }^{3}$ and Tetyana Karlova ${ }^{2}$ \\ ${ }^{1}$ Epidemiology Department, Kharkiv National Medical University, Kharkiv, Ukraine; ${ }^{2}$ Kharkiv Region Laboratory Center of the State \\ Sanitary Epidemiological Service of Ukraine, Kharkiv, Ukraine; ${ }^{3}$ National Aerospace University, Kharkiv, Ukraine
}

\section{Objective}

To estimate the current measles situation in the Kharkiv oblast (eastern region of Ukraine) and to develop ways of improving the surveillance and control of measles in elimination phase during the crisis in Ukraine.

\section{Introduction}

Deterioration of socio-economic conditions in Ukraine created a threat of the spread of communicable diseases, including vaccine preventable diseases [1]. Children in Ukraine routinely receive two doses of the measles-mumps-rubella (MMR) vaccine according to the national immunization schedule. Measles is targeted for elimination in Ukraine [2]. But now Ukraine crisis carries significant public health risk and requires changing tactics of surveillance and epidemiological control against measles.

\section{Methods}

We used the data about reported cases of measles in the region and vaccination of sick people; the results of laboratory tests (ELISA), which confirmed the cases of measles, data about the level of measles immunity among the Kharkiv region population.

\section{Results}

In Ukraine, there is a mandatory registration of cases of measles. Doctor who identified patients with measles or suspected it necessarily informs the surveillance authorities of suspected cases. In 2013 there were 18 cases of measles (incidence was 0.66 per 100000 population) in the Kharkiv oblast. As of August 1, 2014 the incidence was 4.54 per 100000 people (124 cases). As of 01.09.2014, there were 163 probable cases and 128 confirmed cases of measles in the Kharkiv oblast, the cases were distributed equally among the children and adults - 64 cases of measles per each group. It should be noted that among these cases, 48 people were gypsies, who moved from the combat zone (Slavyansk, Donetsk oblast, Lugansk oblast, Ukraine), among them 38 (29.7\%) were children, 10 (7.8\%) - adults. Gypsies often avoid preventive vaccinations. Most cases have been reported in Kharkiv region which was the main place of resettlement of refugees and in Lozovaya region which was their entrepot (Fig.1). The largest number of cases were reported in May and June, 2014, when the flow of refugees from the area of anti-terrorist operation (ATO) increased. Given the fact that at the beginning of the school year (September 1), the flow of refugees from the area of ATO in Kharkiv region grew by people with school-age children and students, a worsening of the measles situation in the area should be expected. In the period before the crisis in Ukraine, an effective syndromic surveillance was implemented in the Kharkiv oblast. Suspected clinical cases of measles (people with maculapapular rash and temperature above $38^{\circ} \mathrm{C}$ ) were laboratory confermed. This approach allowed to identify sick people with measles more fully and to distinguish measles cases from other infections with rash. In Kharkiv oblast laboratory confirmation of cases was noted in $66.4-68.15 \%$ of cases.

\section{Conclusions}

The crisis in Ukraine led to a deterioration of the current measles situation due to refugees from the area of ATO, especially gypsies.

In host territories unvaccinated people need to be vaccinated and people with unknown vaccination status should be laboratory tested and if necessary vaccinated too. For that we should provide opportunities for vaccination of unaccounted population (allocation of vaccines, medical staff etc.)

To achieve the goals of eliminating measles in spite of the crisis in Ukraine implementation of the syndromic surveillance of measles should be continued in order to identify all the cases fully. Laboratories for serological investigation and conformation of suspected cases in Kharkiv should be empowered.

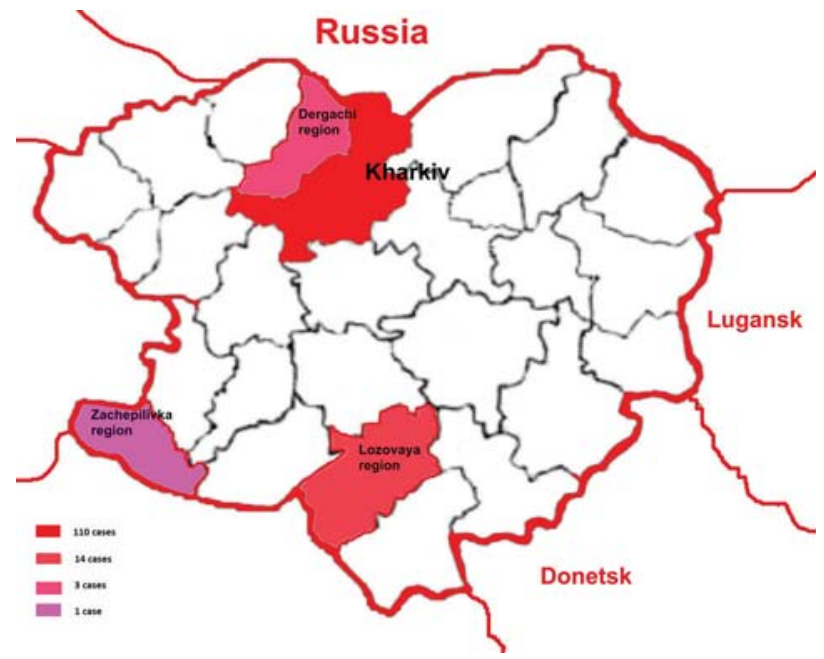

Fig.1. Map of number of measles cases in Kharkiv oblast from 01/01/2014 to $09 / 01 / 2014$

\section{Keywords}

Ukraine; vaccine preventable diseases; a treat of the spread of communicable diseases

\section{References}

1. World Health Organization (WHO). Ukraine crisis. Donor Alert. 15 August 2014.

http://www.who.int/hac/donorinfo/donoralert_ukraine_15aug.pdf?ua=1

2. World Health Organization (WHO). Surveillance Guidelines for measles, Rubella and Congenital Rubella Syndrome in the WHO European Regional Office for Europe: 2012.

\section{*Tetyana Chumachenko}

E-mail: tatalchum@gmail.com 